\title{
SYNOVIAL CELL ACTIVATION INDUCED BY A POLYPEPTIDE MEDIATOR *
}

\author{
C. William Castor \\ Department of Internal Medicine \\ The University of Michigan Medical School \\ Ann Arbor, Michigan 48104
}

\section{The Concept of Synovial Cell Activation}

Rheumatoid arthritis is exclusively a disease of man, and lack of an experimental animal model has impeded progress in understanding the etiology and pathogenesis of this destructive process. At the level of the synovial membrane, the rheumatoid process is characterized by intermittent connective tissue cell proliferation, overproduction of underpolymerized hyaluronic acid, ${ }^{1}$ increased glycolysis, ${ }^{2}$ colonization by various types of inflammatory cells, and abnormalities of the microvasculature. ${ }^{3}$ In the hope of developing a relevant in vitro investigative model, this laboratory established 61 synovial cell strains from normal individuals and patients with different forms of arthritis. The "abnormalities" detected in the rheumatoid cell strains (TABLE 1) were of particular interest, because these characteristics were propagated from one generation of cells to the next.4, 5 Efforts to reproduce the "rheumatoid" characteristics in normal synovial cells by adding rheumatoid sera to the media lead to minor and inconsistent alterations in cellular behavior. ${ }^{6}$

Because evidence for humoral factors capable of inducing "rheumatoid behavior" in normal synovial cells was weak, we next examined the response of normal synovial cells to selected cellular factors. Isolated human peripheral blood lymphocytes, polymorphonuclear leukocytes, and platelets were cocultured with monolayer cultures of normal human synovial cells and found to cause profound changes in culture activity. These changes included decreased medium $\mathrm{pH}$, marked acceleration of hyaluronic acid synthesis, and striking increases in glucose uptake and lactic acid formation. ${ }^{7}$ It soon became clear that slurries of dead leukocytes (frozen-thawed) elicited the same hypermetabolic synovial cell response. Extracts of both syngeneic and allogeneic leukocytes stimulated synovial cells, and because of its protease lability, performance on gel permeation columns, and nondialyzability, the active factor was thought to be a lowmolecular-weight protein. ${ }^{8,9}$ We termed the constellation of accelerated hyaluronate synthesis, increased glucose uptake, and increased lactate formation connective tissue activation, and the cellular mediator(s) that initiate(s) this process was named connective tissue activating peptide (CTAP). ${ }^{9}$ Major sources and actions of CTAP are summarized in FIGURE 1.

* Supported by United States Public Health Service Grant AM-10728 and by the Michigan Chapter of the Arthritis Foundation. 


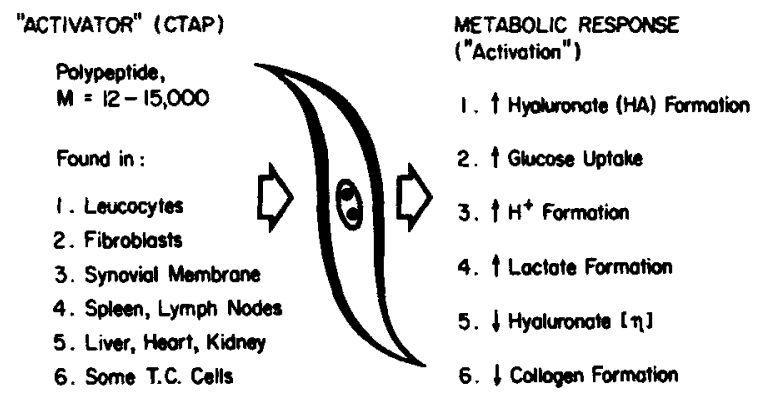

FIGURE 1. CTAP from diverse sources has the capability of interacting in vitro with human synovial cells to produce the consequences listed (right). Although most of the metabolic responses are consistent with in vivo expectations, it seems likely that the depressed collagen formation is an artifact of the closed in vitro system, possibly in part related to substrate limitation. (From Castor ${ }^{14}$ By permission of The Journal of Laboratory and Clinical Medicine.)

\title{
ISOLATION AND CHARACTERIZATION OF CTAP
}

Extraction of CTAP biologic activity from convenient sources, such as human spleen and long-term lymphocyte cultures, has been accomplished with water, buffered saline, $0.25 \mathrm{M}$ sucrose, $0.1 \mathrm{M}$ glycine buffer ( $\mathrm{pH} 2.2$ ), acid ethanol ( $80 \%$ ethanol, $20 \% 1.25 \mathrm{~N} \mathrm{HCl}$ ), and even $0.25 \mathrm{~N}$ sulfuric acid. Early experiments were hampered by the marked lability of CTAP biologic activity, a problem partly resolved when it proved possible to protect the activity by addition of 2-mercaptoethanol to the extraction vehicle. In later experiments, CTAP biologic activity was destroyed by alkylation or mercaptide formation, which fact also suggested that the peptide factor contained an essential sulfhydryl moiety. ${ }^{9}$ Gel permeation chromatography showed that CTAP biologic activity was retarded on Sephadex ${ }^{\circledR}$ G-50 and Bio Gel ${ }^{\circledR}$ P-10 but that it appeared in the void volume from Sephadex G-25 and Bio Gel P-6 columns. CTAP does not bind to DEAE-Sephadex A-25 at neutral $\mathrm{pH}$ but does bind to carboxymethyl- (CM) cellulose 32.

\section{TABLE 1}

"Abnormalities" of Rheumatoid Synovial Cells

\author{
Slower growth rate \\ Increased hyaluronic acid synthesis rate \\ Produce hyaluronic acid of lesser MW \\ Increased glycolytic metabolism \\ Hyporesponsive to cortisol regulation * of mitosis, hyaluronate synthesis, collagen syn- \\ thesis, and cell volume \\ Increased endogenous CTAP
}

* Cortisol, $1.0 \mu \mathrm{g} / \mathrm{ml}$, stimulates mitosis of normal synovial cells by $44 \%$, depresses HA synthesis by $54 \%$, depresses collagen synthesis by $80 \%$, and reduces mean cell volume by $19 \%$. 
Although CTAP was effectively extracted from solid tissues by acidic vehicles, the resultant extracts contained substantial quantities of histones and proved difficult to fractionate. To reduce histone contamination, we have returned to neutral saline extraction in the presence of $0.1 \%$ 2-mercaptoethanol. Our current procedure for isolation of CTAP is depicted in FIGURE 2. A "stage-VI" preparation usually has one to four bands on polyacrylamide disc gel electrophoresis at $\mathrm{pH} 9.5$ in 9 or $15 \%$ gels. Fractions eluted from CMcellulose 32 may be concentrated by rotary evaporation at $30^{\circ} \mathrm{C}$ in the presence of small amounts of glycerol. To prevent loss of peptide due to binding to glassware, it proved helpful to treat with trimethylchlorosilane all glassware in contact with purified CTAP preparations. Both crude and purified CTAP preparations from spleen, cultured lymphocytes, and Hep-2 cells retain biologic activity for weeks if stored frozen at $4^{\circ} \mathrm{C}$ in the presence of $0.1 \% 2$-mercaptoethanol or $0.001 \mathrm{M}$ dithiothreitol or dithioerythritol. Lyophilized preparations retained activity for at least 1 month on storage at $-70^{\circ} \mathrm{C}$. Crude extracts of mixed leukocytes, however, lose biologic activity relatively rapidly.

A preliminary amino acid analysis of virtually homogeneous CTAP derived from long-term human lymphocyte cultures is listed in TABLE 2, The amino acid composition of CTAP from cultured lymphocytes closely resembles that found earlier for human spleen CTAP by semiquantitative chromatographic methods. Aromatic amino acid residues were relatively sparse, whereas dicar-

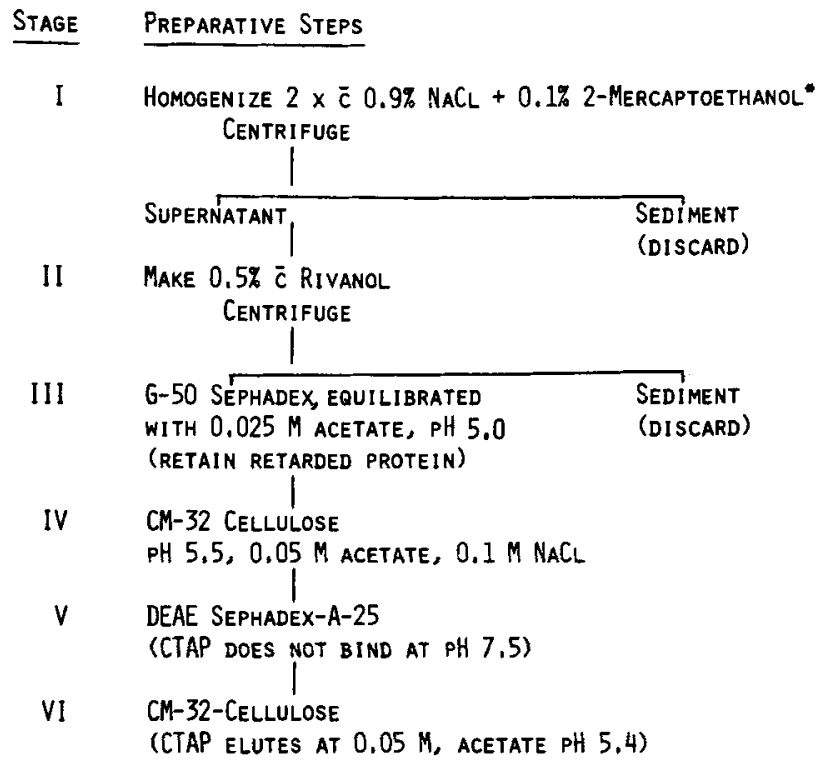

-0.17 2-Mercaptoethanol Was INCLUded in ALL ELUTION VEhICLES

FIGURE 2. With the preparative scheme above, recovery of CTAP appears to range from 50 to $80 \%$. This isolation sequence has been successfully applied to long-term normal lymphocyte cultures, media from such cultures, the Hep-2 cell strain, and to human spleen. 
TABLE 2

Amino ACid Composition of CTAP Fraction: FROM LONG-TERM HUMAN LYMPHOCYTE LINE

\begin{tabular}{lc}
\hline \hline Amino Acid & $\begin{array}{c}\text { Number of } \\
\text { Residues }\end{array}$ \\
\hline Aspartic acid & 14 \\
Glutamic acid & 19 \\
Lysine & 13 \\
Arginine & $5-6$ \\
Histidine & 3 \\
Half-cystine & 3 \\
Methionine & 2 \\
Phenylalanine & 5 \\
Tyrosine & 2 \\
Serine & $10-11$ \\
Threonine & 8 \\
Glycine & 14 \\
Alanine & 11 \\
Valine & 8 \\
Proline & 9 \\
Leucine & 10 \\
Isoleucine & 5 \\
Total residues & 142 \\
Molecular weight & 15,318 daltons \\
\hline \hline
\end{tabular}

* This fraction had a specific biologic activity of 49 CTAP units/mg protein and appeared to be nearly homogeneous on electrophoresis at $\mathrm{pH} 9.5$ in $15 \%$ polyacrylamide gels. The biologic activity elutes from a $1 \times 30-\mathrm{cm}$ Sephadex G-50 fine column at the same volume as does cytochrome $c$.

boxylic acids comprised nearly $25 \%$ of the residues. In view of the apparently basic nature of the peptide, and the ammonia measured during amino acid analysis, it seems likely that a substantial portion of the dicarboxylic acids exist as glutamine and asparagine in the native peptide. The presence of three halfcystine residues confirms the presence of at least one free sulfhydryl group. Chromatography on Sephadex G-50 (F) revealed that lymphocyte CTAP had the same elution volume as cytochrome $c(\mathrm{MW}=12,384$ daltons), a finding in fair agreement with the estimate of 15,318 daltons derived from amino acid analysis. Splenic CTAP also elutes from Sephadex G-50 with the same elution volume as cytochrome $c$.

\section{ASSAY OF CTAP}

Bioassay of CTAP was achieved with $1.0 \times 10^{6}$ normal human synovial cells per T-15 flask. Cells were planted in standard medium (80\% 1066, $10 \%$ human serum, $10 \%$ fetal calf serum supplemented with $l$-glutamine, penicillin, and streptomycin) and allowed to attach and spread on the glass surface for 4-6 hr. Serum-containing medium was then removed and replaced with 2.0 $\mathrm{ml}$ of "assay medium" (Eagle's synthetic medium buffered to $\mathrm{pH} 7.6$ with 0.02 $M$ HEPES). Test samples and appropriate vehicle controls were added in 
volumes that ranged from 0.05 to $0.30 \mathrm{ml}$ per flask, and then the assay flasks were incubated for $40 \mathrm{hr}$ at $35-37^{\circ} \mathrm{C}$. At the conclusion of the incubation period, cell sheets were washed twice with neutral buffered saline, and the protein was measured by the method of Oyama and Eagle. ${ }^{10}$ Hyaluronic acid in the culture medium was measured in terms of its uronic acid moiety by a modified carbazole method ${ }^{11}$ after isolation of the polymer. ${ }^{6}$ Residual medium glucose was measured by a glucose oxidase method, ${ }^{12}$ and lactate was determined by the Barker-Summerson procedure. ${ }^{13}$ Because earlier studies ${ }^{\theta}$ demonstrated that the amount of hyaluronic acid synthesized by the incubated synovial cells was proportional to incubation time and the amount of CTAP added, we arbitrarily defined a "CTAP unit" in terms of the relation

$$
\text { CTAP }=\frac{A_{1}-A_{0}}{10 V}(\text { unit } / \mathrm{ml}),
$$

where $A_{1}$ is the hyaluronic acid synthesis rate $(\mu \mathrm{g} / \mathrm{mg}$ cell protein $/ 24 \mathrm{hr})$ in the experimental flasks, and $A_{0}$ is this measurement in control (vehicle-treated) flasks. The term $V$ represents the volume $(\mathrm{ml})$ of test material.

\section{Biologic Significance of CTAP}

To evaluate the CTAP content of an evolving granuloma in vivo, cotton pellets were implanted subcutaneously in Sprague-Dawley rats, and the resultant granulomas were harvested at intervals after implantation. ${ }^{14}$ The CTAP concentrations in granulomas (units of CTAP/100 $\mu \mathrm{g}$ DNA) were elevated at Day 4, reached a peak at Day 7, and returned to low levels by Day 14 (FIGURE 3 ). The hyaluronic acid concentrations in the granulomas were also greatest at Day 7, whereas sulfated mucopolysaccharides reached their greatest concentrations by Day 14 (Figure 4). Collagen was present in high concentrations by Day 7 and increased slightly over the next 3 weeks. Polymorphonuclear leukocytes were the dominant cell type at Day 4 , but by Day 7 , the granuloma was primarily populated by fibrocytes and foreign body giant cells. The elevated level of CTAP found early in the inflammatory process is consonant with its postulated role as a regulator of the transition from the exudative to the reparative phase of inflammation. Further, the concomitant peak concentration of hyaluronate in the granuloma is in accord with the in vitro actions of CTAP that we have described.

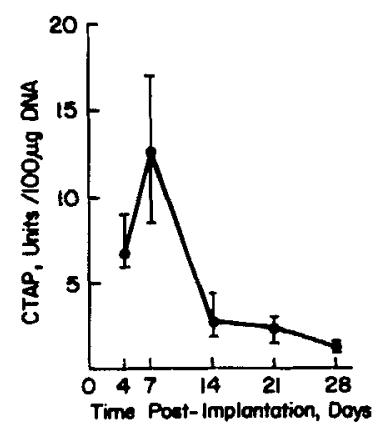

Figure 3. CTAP flux in cotton pellet granulomas followed for 28 days. Vertical bars at data points reflect the range of the measurements. (From Castor. ${ }^{14}$ By permission of The Journal of Laboratory and Clinical Medicine.) 
Figure 4. The time course of $\mathrm{HA}$ and sulfated glycosaminoglycan concentrations in rat cotton pellet granulomas is recorded. Vertical bars at the data points indicate the standard error of the mean from four sets of measurements for $\mathrm{HA}$ and five sets of measurements for the sulfated glycosaminoglycans. The two early HA concentrations (Days 4 and 7 ) were significantly $(\mathrm{p}<0.01)$ larger than those at Days 14 and 21. (From Castor. ${ }^{14}$ By permission of The Journal of Laboratory and Clinical Medicine.)

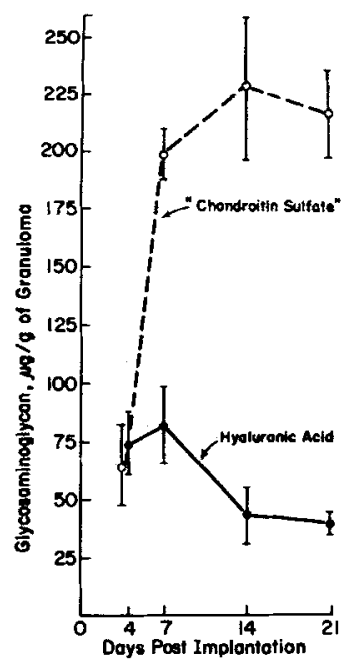

Rheumatoid synovial cells in vitro were relatively unresponsive to exogenous CTAP, ${ }^{15}$ an observation that suggested that rheumatoid cells might be "abnormal" (TABLE 1) by virtue of increased endogenous CTAP content. When CTAP was extracted from seven normal and seven rheumatoid cell strains, and the extracts were assayed simultaneously, the rheumatoid strains were found to have approximately four times the CTAP activity found in normal synovial cells. Most of the abnormal metabolic properties listed in TABLE 1 for rheumatoid cell strains may be attributable to the elevated endogenous CTAP levels in rheumatoid cells. Although detection of increased cellular CTAP activity may come closer to identifying a primary defect in rheumatoid synovial cells, there is no obvious etiologic reason for this phenomenon. Because the retention time of CTAP added to normal cultures is only a few days at most, it seems unlikely that increased endogenous CTAP in rheumatoid cells is a legacy from previous contacts with inflammatory leukocytes.

Plasma levels of CTAP have been found elevated in more than two-thirds of patients with active rheumatic diseases, whereas patients whose disease was suppressed with glucocorticoid or cytotoxic agents had CTAP levels in the normal range. ${ }^{16}$ Although CTAP is detectable in plasma, more than $60 \%$ of the biologic activity in circulating blood resides in the leukocytes and platelets. Joint fluid from patients with traumatic arthritis, osteoarthritis, and rheumatoid arthritis contained detectable concentrations of CTAP, whereas the leukocytes from these effusions displayed very little activity.

Splenic tissue from infants has repeatedly proved to be a poor source of CTAP. In the same vein, extracts of fetal mouse brain and rat limb buds (19 day) had low, although measureable, levels of this biologic activity. Crude extracts of human spleens involved by plasmacytic myeloma also exhibited low concentrations of CTAP. Most startling was the observation that circulating leukocytes from several types of uncontrolled human leukemia had virtually no CTAP activity. It is unclear whether these "CTAP-poor" states, while sharing the characteristic of being inadequately or abnormally differentiated, have a 
common denominator that explains these findings. The possibility of inhibitory substances in the crude extracts needs serious study.

\section{Specificity of Target Cells and Agonists}

\section{The Target Cells}

The spectrum of connective tissue cells capable of exhibiting increased hyaluronate synthesis and energy utilization on exposure to CTAP has received inadequate attention. To date, only synovial fibroblasts (human and canine), human retroorbital fibroblasts, and mesothelioma cells have been shown to be responsive to "conventional" CTAP (derived from human spleen, leukocytes, Hep-2 tissue culture cells, and canine spleen). Dermal fibroblasts in cell culture are not stimulated to produce incremental hyaluronate by "conventional" CTAP but do respond to extracts of dermal fibroblasts themselves." Human dermal fibroblasts also demonstrate increased glycosaminoglycan synthesis on exposure to dibutyryl cyclic AMP and prostaglandin (PG) $\mathrm{E}_{1},{ }^{1 \mathrm{i}},{ }^{1 \mathrm{~N}}$ It is possible that there may be multiple CTAP-like substances with tissue or organ specificities. Studies wherein primary fibroblast strains from many anatomic sites are exposed to purified, characterized CTAP from many sources should shed light on this question.

\section{The Agonists}

As can be seen in TABLE 3, several agents are capable of stimulating synovial cells to form increased quantities of hyaluronic acid. It is clear, however, that in most cases, these agonists are not found in such supraphysiologic concentrations in vivo, and some of the other agents do not occur naturally. CTAP is the most potent agent for stimulating synovial cell hyaluronate synthesis, followed by $\mathrm{PGE}_{1}$, dibutyryl cyclic AMP, and endotoxin. Both $\mathrm{PGE}_{1}$ and dibutyryl cyclic AMP not only stimulate synovial cells directly in the high concentrations recorded in TABLE 3 but will also potentiate the effect of CTAP when they are added to cultures in low concentrations that are not stimulatory in their own right. ${ }^{17}, 18$ The stimulatory effect of endotoxins probably derives in large part from the lipid-A component of these molecules. ${ }^{19}$ There is some evidence to suggest that endotoxin may activate synovial cells by inducing increased levels of endogenous CTAP. ${ }^{20}$ Some low-molecular-weight basic materials that do not display "CTAP-stimulating" activity are listed in TABLE 4. In some cases, the agents appear to inhibit basal hyaluronate synthesis. Poly-Larginine ( $\mathrm{MW}=65,000$ ) is actually a potent in vitro inhibitor of CTAP-induced synovial cell activation.

\section{Inhibitors of Synovial Cell Activation}

A partial list of agents that interfere with CTAP-induced activation of synovial cells is found in TABLES 5 and $6 .^{18,21-23}$ Actinomycin D inhibits activation only if added within $2 \mathrm{hr}$ of the CTAP stimulus, whereas cycloheximide is effective when added as late as $6 \mathrm{hr}$ post CTAP. The conventional anti- 
TABLE 3

Synovial Cell Activation: Effective Agents

\begin{tabular}{lccc}
\hline \hline \multicolumn{1}{c}{ Agent } & $\begin{array}{c}\text { Concentration } \\
(\mu \mathrm{g} / \mathrm{ml})\end{array}$ & $\begin{array}{c}\text { Incremental } \\
\text { Hyaluronate } \\
\text { (exp/cont) }\end{array}$ & $\begin{array}{c}\text { "Specific" } \\
\text { Ratio } \\
\text { (exp/cont } \\
\times \mathrm{mg})\end{array}$ \\
\hline Vehicle & - & 1.00 & - \\
CTAP & 2.4 & 10.05 & 4186.0 \\
Prostaglandin $\mathrm{E}_{1}$ & 1.0 & 3.18 & 3180.0 \\
Db cAMP & 400.0 & 7.03 & 17.6 \\
Endotoxins $\dagger$ & 40.0 & 6.00 & 150.0 \\
TSH $\ddagger$ & 50.0 & 2.12 & 42.5 \\
LH $¥$ & 50.0 & 2.14 & 42.7 \\
CGH & $12.5 \S$ & 1.24 & 33.4 \\
Poly-L-histidine & 50.0 & 1.67 & 249.3 \\
Poly I:C & 25.0 & 6.23 & \\
\hline \hline
\end{tabular}

* Prepared from human spleen, exhibits two bands by polyacrylamide gel electrophoresis.

$\dagger$ S-typhosa 0901.

$\ddagger$ Bovine (NIH).

\$International units (IU).

TABLE 4

Synovial Cell Activation: Ineffective Agents

\begin{tabular}{lcc}
\hline \hline \multicolumn{1}{c}{ Substance Tested } & $\begin{array}{c}\text { Concentration } \\
(\mu \mathrm{g} / \mathrm{ml})\end{array}$ & $\begin{array}{c}\text { Incremental } \\
\text { Hyaluronate } \\
(\mathrm{exp} / \text { cont })\end{array}$ \\
\hline Vehicle & - & 1.0 \\
Lysozyme & 50 & 1.2 \\
Cytochrome $c$ & 50 & 1.2 \\
Ribonuclease & 50 & 1.0 \\
Eosinophil granule basic protein $\dagger$ & 30 & 1.0 \\
Protamine & 25 & 0.9 \\
Spermine & 25 & 0.8 \\
Poly-L-lysine & 50 & 1.2 \\
Poly-L-arginine & 50 & 0.1 \\
Histones (Sigma) & & 0.7 \\
Calf thymus mixture & 25 & 1.1 \\
Calf thymus mixture & 150 & 0.5 \\
Type III (lysine rich) & 150 & 0.7 \\
Type IV (f $\mathrm{f}_{3}$, arginine rich) & 150 & 0.8 \\
Type VI (f (an $\left._{2 \mathrm{a}}\right)$ & 150 & 0.4 \\
Type VIII ( $\left.\mathrm{f}_{3}\right)$ & 150 & \\
\hline \hline
\end{tabular}

* Rates expressed as $\mu \mathrm{g} \mathrm{HA} / \mathrm{mg}$ cell protein $/ 24 \mathrm{hr}$.

$\dagger$ A gift of Dr. Gerald J. Gleich (preparation described in J. Exp. Med. 137: 1459, 1973). 
TABLe 5

Inhibitors of Synovial Cell Activation

\begin{tabular}{lc}
\hline \hline \multicolumn{1}{c}{ Agent } & $\begin{array}{c}\text { Effective } \\
\text { Concentration } \\
(\mu \mathrm{g} / \mathrm{ml})\end{array}$ \\
\hline Inhibitors of RNA Synthesis & \\
Actinomycin D & 0.25 \\
Mithramycin & 0.50 \\
Chromomycin As & 100.00 \\
Acridine orange & 7.90 \\
a-Amanitine & 3.07 \\
Inhibitors of Protein Synthesis & 10.00 \\
Cycloheximide & 0.25 \\
Acetoxycycloheximide & 1.25 \\
Puromycin & $4 \times 10^{-5} \mathrm{M}$ \\
Inhibitors of Energy Metabolism & $2 \times 10^{-3} \mathrm{M}$ \\
2,4-Dinitrophenol & \\
Sodium fluoride & 150.00 \\
Antinflammatory Drugs & 75.00 \\
Acetylsalicylic acid & 15.00 \\
Phenylbutazone & 5.00 \\
Indomethacin & 4.00 \\
Meclofenamic acid & 80.00 \\
Flufenamic acid & 1.00 \\
Mefenamic acid & \\
Cortisol & \\
\hline \hline
\end{tabular}

TABLE 6

Inhibitors of Synovial Cell Activation

\begin{tabular}{cc}
\hline \multicolumn{1}{c}{ Agent } & Effective Concentration \\
\hline Prostaglandin Antagonists & \\
7-Oxa-13-prostynoic acid & $50.0 \mu \mathrm{g} / \mathrm{ml}$ \\
Polyphloretin phosphate & $50.0 \mu \mathrm{g} / \mathrm{ml}$ \\
$\beta$-Adrenergic Blocking Agents & \\
Propranolol & $10^{-5}$ to $10^{-4} \mathrm{M}$ \\
D-Propranolol & $10^{-4} \mathrm{M}$ \\
Alprenolol & $10^{-5}$ to $10^{-4} \mathrm{M}$ \\
Butoxamine & $10^{-4} \mathrm{M}$ \\
a-Adrenergic Blocking Agents & $10^{-4} \mathrm{M}$ \\
Phentolamine & $10^{-4} \mathrm{M}$ \\
Chlorpromazine & $10^{-4} \mathrm{M}$ \\
Other Agents & $0.5 \times 10^{-4} \mathrm{M}$ \\
Imipramine & \\
Ethacrynic acid & \\
\hline \hline
\end{tabular}


inflammatory drugs (TABLE 5) are effective inhibitors at levels usually achieved in the plasma of patients who receive these agents. 7-Oxa-13-prostynoic acid not only blocks CTAP-induced hyaluronate (HA) synthesis but also interferes with $\mathrm{PGE}_{1}$ stimulation of $\mathrm{HA}$ synthesis in synovial cells. The adrenergic blocking agents and imipramine probably do not act via specific receptor site blockade but may be active through their membrane-stabilizing properties. Ethacrynic acid, imipramine, and the adrenergic blocking agents suppress HA synthesis, even when added to cultures $16 \mathrm{hr}$ post CTAP, and the bulk of the evidence suggests that they act on the HA-synthesizing mechanism itself.

\section{Mechanism of CTAP-Induced Synovial Cell Activation}

The mechanism by which CTAP induces synovial cell activation may be tentatively represented as illustrated in FIGURE 5. CTAP may be visualized as

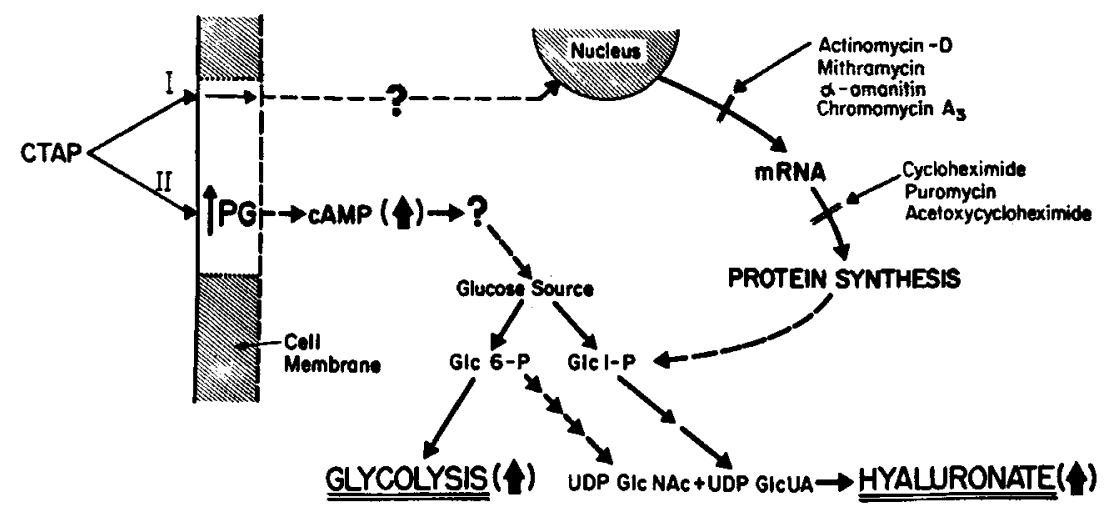

FIGURE 5. Synovial cell activation. CTAP is represented as interacting with a twocomponent receptor site and triggering two essential, but independent, reaction sequences that result in "activation" of the synovial cell.

interacting with a complex cell membrane receptor site that possesses at least two essential components. Component I initiates the sequence of events in the upper arcade that leads to obligatory protein synthesis (presumably enzymes important to the glycolytic and HA synthesis pathways) and prepares the cell for large-scale synthesis of hyaluronic acid. Component II is believed to initiate a prostaglandin-cyclic AMP interaction that mobilizes both energy and carbon to meet the needs of the impending synthetic effort. Evidence to support a role for endogenous (synovial) prostaglandin synthesis includes inhibition of CTAP-induced activation by prostaglandin antagonists; inhibition of CTAPinduced activation by inhibitors of prostaglandin synthesis, such as aspirin and indomethacin; reversal of indomethacin inhibition by $\mathbf{P G E}_{1}$ and dibutyryl cyclic AMP; and similar magnitude of accumulation of synovial cell cyclic AMP caused by CTAP and "potentiating" levels of exogenous PGE .

Our belief that the receptor site must have at least two components derives from two observations. First, both cortisol and cycloheximide block the action 
FIGURE 6. Simple inflammation. CTAP is represented as a signal that connects the acute and reparative phases of a simple inflammatory response to injury.
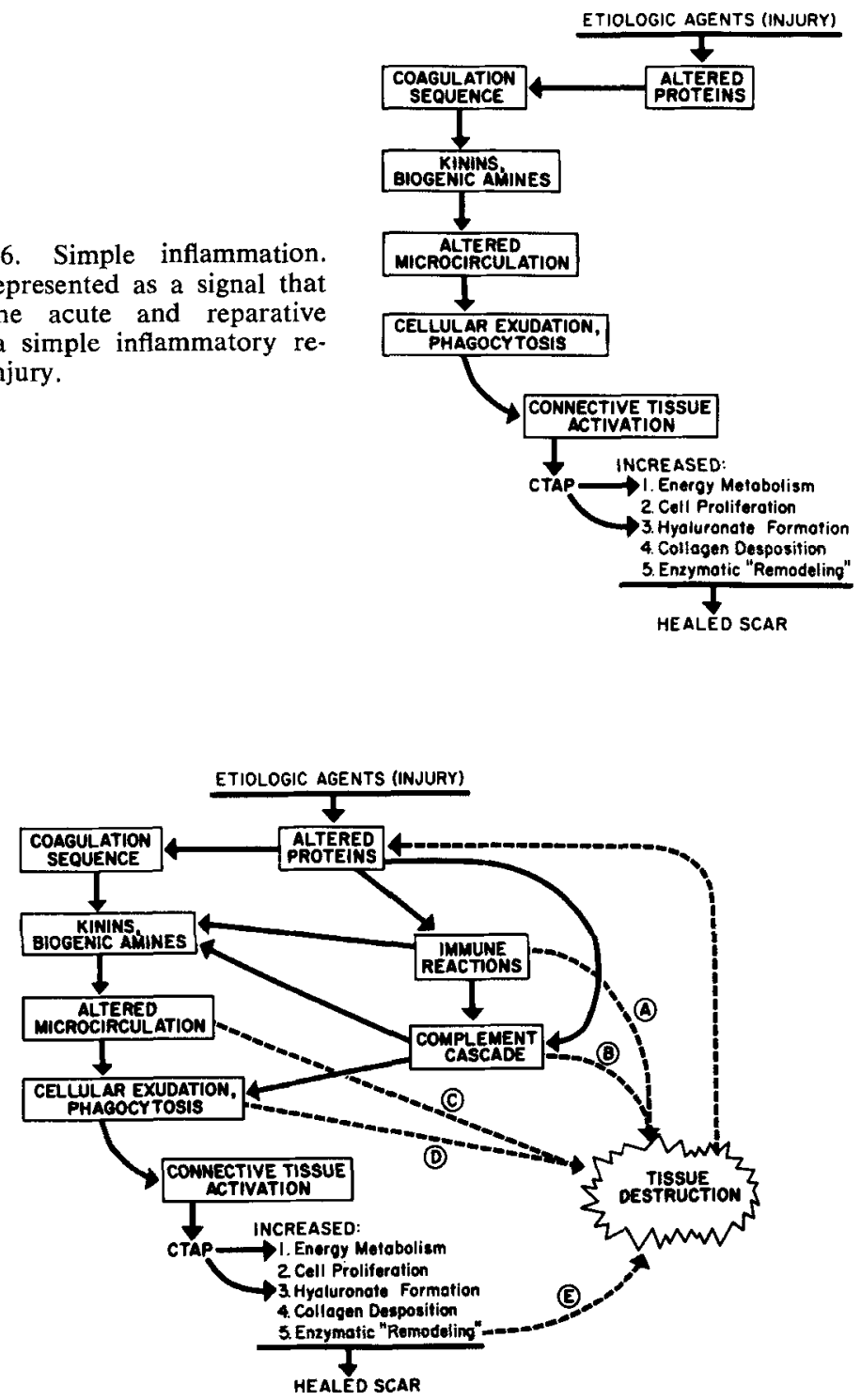

FIGURE 7. Rheumatoid inflammation. The coupling of immune processes and the complement mechanism to simple inflammation suggest many avenues for tissue destruction and many reasons for the "self-perpetuating" character of chronic synovial inflammation. Dashed lines indicate possible alternate routes that lead to tissue destruction, e.g.: A, via immune cytolysis; B, via lysosomal enzymes; $\mathrm{C}$, via anoxia; D \& E, via enzymatic attack. (From Castor. ${ }^{22}$ By permission of Arthritis \& Rheumatism.) 
of CTAP. Second, neither cortisol nor cycloheximide inhibit the "CTAPmimicking" effects of either PGE, or dibutyryl cyclic AMP.

In Figure, 6 the locus of CTAP-induced connective tissue activation is shown at the junction of the exudative and reparative phases of simple inflammation. It is possible that other "signals" may initiate cell proliferation, collagen synthesis, and so on. If simple inflammation is amplified by addition of immune reactions, the overall picture might be represented as illustrated in FIGURE 7. In the context of this scheme, the performance of a drug in chronic inflammation would depend on how effectively it inhibited a particular pathway and on the relative importance of the different pathways with respect to tissue destruction and perpetuation of the inflammatory process. Presently, we have no quantitative methods for weighing the importance of the different components of the inflammatory process outlined in FIGURE 7 , either in terms of their proportional contributions to tissue dysfunction and destruction or in terms of their contribution to the self-perpetuating character of chronic inflammation.

\section{ACKNOWLEDGMENT}

I thank Dr. C. H. Williams, Jr., Veterans Administration Hospital, Ann Arbor, Mich., for performing the amino acid analysis.

\section{REFERENCES}

1. Castor, C. W., R. K. Prince \& M. J. Hazelton. 1966. Hyaluronic acid in human synovial effusions; a sensitive indicator of altered connective tissue cell function during inflammation. Arthritis Rheumat. 9: 783-794.

2. FalchuK, K. H., E. J. Goetzl \& J. P. Kulka. 1970. Respiratory gases of synovial fluids. An approach to synovial tissue circulatory-metabolic imbalance in rheumatoid arthritis. Amer. J. Med. 48: 223-231.

3. GoldIE, I. 1970. The synovial microvascular derangement in rheumatoid arthritis and osteoarthritis. Acta Orthopaed. Scand. 40: 751-764.

4. Castor, C. W. \& E. L. DoRstewitz. 1966. Abnormalities of connective tissue cells cultured from patients with rheumatoid arthritis. I. Relative unresponsiveness of rheumatoid articular cells to hydrocortisone. J. Lab. Clin. Med. 68: 300-313.

5. Castor, C. W. 1971. Abnormalities of connective tissue cells cultured from patients with rheumatoid arthritis. II. Defective regulation of hyaluronate and collagen formation. J. Lab. Clin. Med. 77: 65-75.

6. Castor, C. W., D. Wright \& R. B. Buckingham. 1968. Effects of rheumatoid sera on fibroblast proliferation and hyaluronic acid synthesis. Arthritis Rheumat. 11: 652-659.

7. Yaron, M. \& C. W. Castor. 1969. Leukocyte-connective tissue cell interaction. I. Stimulation of hyaluronate synthesis by live and dead leukocytes. Arthritis Rheumat. 12: 365-373.

8. CAstor, C. W. \& M. Yaron. 1969. Leukocyte-connective tissue cell interaction. II. The specificity, duration, and mechanism of interaction effects. Arthritis Rheumat. 12: 374-386.

9. CASTOR, C. W. 1971. Connective tissue activation. I. The nature, specificity, measurement and distribution of connective tissue activating peptide. Arthritis Rheumat. 14: 41-54.

10. Oyama, V. I. \& H. Eagle. 1956. Measurement of cell growth in tissue culture with a phenol reagent (Folin-Ciocalteau). Proc. Soc. Exp. Biol. Med. 91: 305-307. 
11. Bitter, T. \& H. M. MuIR. 1962, A modified uronic acid carbazole reaction. Anal. Biochem. 4: 330-334.

12. Gibson, Q. H., B. E. P. Swoboda \& V. Massey. 1964. Kinetics and mechanism of action of glucose oxidase. J. Biol. Chem. 239: 3927-3934.

13. Barker, S. B. \& W. H. Summerson. 1941. The colorimetric determination of lactic acid in biological material. J. Biol. Chem. 138: 535-554.

14. Castor, C. W. 1973. Connective tissue activation. V. The flux of connective tissue activating peptide during acute inflammation. J. Lab. Clin. Med. 81: 95-104.

15. Castor, C. W. 1971. Connective tissue activation. II. Abnormalities of cultured rheumatoid synovial cells. Arthritis Rheumat. 14: 55-66.

16. HoRn, J. R. \& C. W. CAstoR. 1972. Connective tissue activation: the presence of connective tissue activating peptide in plasma and synovial fluid. Ann. Intern. Med. 76: 881 .

17. CAstor, C. W. 1974. Connective tissue activation. VI. The effects of cyclic nucleotides on human synovial cells in vitro. J. Lab. Clin. Med. 83: 46-55.

18. CAstor, C. W. 1975. Connective tissue activation. VII. Evidence supporting a role for prostaglandins and cyclic nucleotides. J. Lab. Clin. Med. 85: 392-404.

19. Buckingham, R. B. \& C. W. CAstor. 1972. The effect of bacterial products on synovial fibroblast function: hypermetabolic changes induced by endotoxin. J. Clin. Invest. 51: 1186-1194.

20. Buckingham, R. B. \& C. W. Castor. 1975. Endotoxin-induced "rheumatoid behavior" in normal human synovial fibroblasts. J. Lab. Clin. Med. 85: 422435.

21. Castor, C. W. 1972. Connective tissue activation. III. Observations on the mechanism of action of connective tissue activating peptide. J. Lab. Clin. Med. 79: 285-301.

22. Castor, C. W. 1972. Connective tissue activation. IV. Regulatory effects of antirheumatic drugs. Arthritis Rheumat. 15: 504-514.

23. CASTOR, C. W. 1974. Connective tissue activation: studies of a mediator and its inhibition by unusual drugs. Clin. Res. 22: 641A.

\section{Discussion}

DR. M. ZIFF: If you start a rheumatoid synovial cell culture, does it act like a rheumatoid synovial cell culture through many, many generations, as though it's producing CTAP all the time?

DR. CASTOR: That's correct.

DR. ZIFF: Now, if you add CTAP to a normal synovial cell culture and stimulate it, does it stay that way forever?

Dr. Castor: No, if we add CTAP on a one-time basis, we can demonstrate the hypermetabolic effects for as long as a month. If, however, we add CTAP daily or three times a week to normal cultures and not only follow the metabolic parameters but also extract the synovial cells for CTAP, we can recover the added CTAP for a few days after it has been omitted from the medium.

DR. ZIFF: It runs down.

DR. CASTOR: It runs down very rapidly. This experience with normal cultures suggests that the increased amount of CTAP found in rheumatoid fibroblasts is unlikely to be a legacy from their previous contact with leukocytes in the joint.

DR. ZiFf: Have you ever injected it intraarticularly? 
DR. CASTOR: When you inject both heat-inactivated and nonheat-inactivated CTAP into dog joints, there is substantial stimulation of hyaluronate synthesis and lactate formation on the experimental side, and the synovial membrane exhibits marked reduplication of the lining cell layer.

Dr. ZiFF: Do you think this factor could be responsible for the hypertrophy and proliferation of the lining there?

Dr. CASTOR: I can't be certain. The reason that this experiment wasn't presented is that we also stimulated a substantial influx of polymorphonuclear leukocytes into the joint, and the effect of the CTAP and other actions of the leukocytes couldn't be separated.

Dr. S. WIENER (Long Island Jewish Hillside Medical Center, New Hyde Park, N.Y.): Is it true that CTAP has no effect on dermal fibroblasts, only on synovial fibroblasts?

Dr. CASTOR: That's one of the puzzling aspects of this study, Dr. Wiener. What we would call conventional CTAP, that which is derived from either lymphocytes or the spleen, has virtually no effect on dermal fibroblasts.

However, if we use the same extraction and purification procedures and extract dermal fibroblasts themselves, we get a CTAP-like material that will stimulate both dermal and synovial fibroblasts. So, there may be more than one kind of CTAP.

Dr. Craig (Boston, Mass.): CTAP is probably very specific in terms of what it affects. It affects fibroblasts from specific sources and only synovial cells. Is that right?

Dr. CASTOR: This material has been studied in a few other cell systems. Human retroorbital fibroblasts in culture are stimulated by CTAP, as are human mesothelioma tumor cells. We presently are isolating fibroblast strains from other anatomic locations to work out this question.

Dr. Craig: But, when you take CTAP from a human source and add it to animal fibroblasts, there is no effect, is that correct?

Dr. Castor: Dog synovial membrane cells are stimulated by both human and canine CTAP, and that is the only nonhuman synovial cell source that we've examined. 